Estudios sobre armas antiguas, arte militar y vida cultural en oriente y occidente XXXII (2012), pp. 103-120

ISSN : 0436-029X

doi: 10.3989/gladius.2012.0006

\title{
EL ASTA DE LA LANZA: LOS MECANISMOS DE FINANCIACIÓN DE LA GUERRA DURANTE EL REINADO DE ALFONSO XI (1312-1350)*
}

\author{
THE SHAFT OF THE LANCE: FINANCING WAR DURING \\ THE REIGN OF ALFONSO XI (1312-1350)
}

POR

NicolÁs Agrait**

\section{RESUMEN - ABSTRACT}

Para entender cómo fue posible el triunfo militar de Alfonso XI sobre sus enemigos hay que mirar más allá de su valor, liderazgo y estrategias y tácticas bélicas, y estudiar a fondo los mecanismos que utilizó para sufragar los elevados costes de sus múltiples campañas y los gastos de defensa ordinarios. Además de utilizar los recursos fiscales de la Corona y los tributos tradicionales relacionados a la guerra, Alfonso dependió, cada vez más, de impuestos extraordinarios, como monedas foreras, servicios, alcabalas, la suspensión temporal de exenciones fiscales a nivel local, recursos monetarios eclesiásticos, empréstitos, y ventas de patrimonio real. Estos mecanismos financieros abrieron nuevas fuentes de ingreso para financiar sus ambiciones militares y realmente constituyeron una de las razones fundamentales del éxito de Alfonso como monarca y comandante militar.

To understand how it was possible for Alfonso XI to triumph militarily over his enemies, it is not enough to look at his courage, leadership and military strategies and tactics. One also has to study in depth the mechanisms he used to cover the high costs of his multiple campaigns and ordinary defense costs. In addition to the Crown's regular fiscal resources and those taxes specifically related to warfare, Alfonso came to depend more and more on extraordinary levies, like monedas foreras, servicios, alcabalas, the temporary suspension of fiscal exemptions at the local level, the wealth of the Church, loans, and the sale of parts of the royal patrimony. These financial mechanisms opened up new sources of revenue to feed his military ambitions and truly constituted one of the most fundamental reasons for Alfonso's success as a monarch and commander.

\section{Palabras Clave - Keywords}

Alfonso XI; Historia Militar; Reino de Castilla; Edad Media.

Alfonso XI; Military History; Castile; Middle Ages.

Harto difícil sería argumentar contra el distinguido historial militar del monarca Alfonso $\mathrm{XI}$, desde sus conquistas poco tiempo después de tomar las riendas del poder al fin de su larga minoría, su sumisión de la nobleza, los conflictos fronterizos con Navarra y Portugal, hasta

* Como autor deseo expresar mi sincero agradecimiento al profesor Francisco Gago-Jover del College of the Holy Cross (Worcester, Massachusetts, EE.UU.), cuya lectura, comentarios y sugerencias sobre este artículo fueron de inestimable utilidad.

** Profesor auxiliar, Long Island University-Brooklyn, Departamento de Historia, 1 University Plaza, Brooklyn, New York 11201, nicolas.agrait@liu.edu 
sus victorias sobre las fuerzas conjuntas de los benimerines y los granadinos en la batalla del Salado (1340) y la conquista de Algeciras (1344). Estas hazañas demuestran ampliamente su decidido carácter y su pericia militar y política. Sin embargo, el caracterizar estos triunfos estrictamente desde el punto de vista de Alfonso, es decir como exempla de su fortaleza personal y desempeño como comandante durante momentos tan difíciles, es pintar un cuadro simplista e incompleto en cuanto a lo que a la práctica de la guerra durante este período se refiere. En otras palabras, liderazgo y estrategia son dos, pero sólo dos, importantes aspectos de la administración militar. Hay que analizar, además, las áreas de ideología, logística, reclutamiento, fortificación y financiación entre otras para obtener una imagen completa y correcta de este complejo fenómeno histórico.

El propósito del presente estudio es el dilucidar los mecanismos fiscales relacionados con la práctica de la guerra durante la primera mitad del siglo XIV. En concreto, la grandeza de Alfonso en alcanzar sus objetivos militares recae no sólo en su capacidad para maximizar los recursos financieros castellanos existentes a su disposición, como las rentas reales, la cruzada, la apropiación de recursos locales, entre otros, sino además en su talento para implementar nuevos instrumentos fiscales - los servicios extraordinarios y las alcabalas. En otras palabras, él pudo extraer y explotar recursos adicionales en donde parecería no ser posible. De no haberlo hecho, las grandes campañas de la última década de su reinado habrían resultado en penosas derrotas y la historia de Castilla sería muy distinta.

El primer asunto de importancia es conocer qué clase de recursos eran necesarios para llevar a cabo una operación militar y por qué éstos ascendían a tan exorbitantes niveles. Los gastos relacionados con cualquier campaña militar precisaban, desde su inicio, de un gran esfuerzo para recaudar los fondos necesarios y el compromiso necesario para administrarlos. En la Europa de los siglos XIII y XIV, sin que Castilla fuera una excepción, los gastos de índole militar aumentaron en su conjunto con la mayor frecuencia y escala de las campañas ${ }^{1}$. Los generales de la época tuvieron, por lo tanto, que ajustarse a estas nuevas exigencias.

Todo comandante capacitado estaba obligado a considerar en todo momento no sólo cómo cubrir los costes inmediatos sino, además, cómo aprovechar cualquier oportunidad para reponer sus recursos y cómo utilizarlos de la forma más eficiente. ¿Cuáles eran estos gastos? El desembolso fundamental y más costoso era para el aprovisionamiento de las tropas, caballos y demás acémilas. Esto era indispensable ya que los soldados sujetos a persistentes carencias de víveres podrían perder rápidamente el deseo y la capacidad para batallar de forma eficaz, y serían mucho más susceptibles a la insubordinación o incluso la deserción. La falta de fuentes castellanas fidedignas durante el reinado de Alfonso no permite hacer un cálculo preciso sobre las vituallas necesarias para sustentar un ejército en campaña, ni cuál sería su precio. Sin embargo, si se utiliza el estudio de Manuel Sánchez Martínez sobre las expediciones de Alfonso IV de Aragón (1327-36) como una aproximación, se puede afirmar que se necesitaban diariamente alrededor de 1,256 kg de harina por soldado y alrededor de $10 \mathrm{~kg}$ de cebada por montura ${ }^{2}$. Esto implica que una pequeña fuerza armada de cien caballeros con una infantería de cuatrocientos hombres consumiría aproximadamente $18.840 \mathrm{~kg}$, o 35 cahíces andaluces, de harina, y sus monturas requerirían $45.500 \mathrm{~kg}$, o 85 cahíces andaluces, de cebada cada mes ${ }^{3}$.

\footnotetext{
1 Contamine (1984), 91; Grassotti (1990), 3445.

2 Sánchez Martínez (1993), 527-28. El historiador John France llega al resultado similar de 1 kg. en pan, o el equivalente calórico, como la cantidad que cada soldado debía consumir a diario. France (1999), 35.

3 Aquí defino el cahíz siguiendo los pesos y medidas en Ladero Quesada (1973), 15. Es más difícil calcular cuánto costaría en metálico ya que el coste de los granos varía según la localidad, circunstancias y temporada. Sin embargo, varias cartas reales al Obispo de Jaén mencionan el precio de 18 maravedíes por cahíz en septiembre de 1342, el cual aumentaría a 24 maravedíes en diciembe del mismo año (Rodríguez Molina, 1983, docs. 52-53, vol. 1, pp. 137-40, 200-01).
} 
Esta aproximación no incluye otros alimentos como la carne, el vino u otros que ciertamente formarían parte de la dieta de los combatientes, el coste de material de guerra como armamento, herraduras y herramientas, ni cualquier gasto como la construcción y reparo de ingenios, si fuese necesario sitiar una plaza. Si la campaña requería apoyo naval, como la del Salado (1340) o en particular durante el cerco de Algeciras (1342-44) los costes ascendían a niveles astronómicos ${ }^{4}$.

Para entender cómo Alfonso XI pudo sufragar tan elevados gastos militares conviene examinar en primer lugar los impuestos que la hacienda real tenía a su disposición para estos casos: yantares, acémilas, galera, fonsadera, el quinto real y las parias.

En su origen, los yantares consistían en la obligación feudal de los vasallos de proporcionar al rey comida y hospitalidad cuando éste los visitase. Durante el siglo XII, los yantares, en vez de recaudarse en el momento de la visita real, se convirtieron en un tributo anual, asumiendo que el monarca visitaría las localidades por lo menos una vez cada año ${ }^{5}$. En las Cortes de Palencia (1286), se estableció cuales debían ser las cuantías que, como yantares, debían abonar a la hacienda real las localidades sujetas a este tributo: 600 maravedíes para el rey, 300 para el príncipe-heredero, 200 para la reina ${ }^{6}$. Estas fueron confirmadas por Fernando IV (1295-1312) en 1307 y cinco años después se añadieron las cuantías de 205 maravedíes para el Adelantado Mayor y 150 para los merinos mayores ${ }^{7}$. A pesar de que la inflación en Castilla y las numerosas exenciones fiscales concedidas por la Corona a diversos individuos, lugares e instituciones eclesiásticas redujeron su cuantía en término reales, la recaudación de los yantares siguió siendo un importante recurso fiscal para la hacienda real castellana durante el siglo XIV. Durante el reinado de Alfonso, se volvió habitual la recaudación de este tributo aunque el monarca no visitase las localidades específicas, siempre y cuando el rey estuviese en campaña, costumbre que se reafirmó durante el reinado de Pedro I (1350-69) ${ }^{8}$.

Ya que las bestias de carga eran indispensables para cualquier operación militar más allá de cabalgadas limitadas, el gravoso trabajo de reunir, alimentar y dirigir las bestias se solventaba en Castilla mediante el impuesto de acémilas. Este deber fiscal se le imponía a todo pueblo como parte de la concesión de un fuero por parte de la Corona y era específicamente el deber de proveer bestias y/o dineros para adquirirlas durante una campaña militar. La Corona se aferró incondicionalmente a este impuesto, incluso en localidades que se habían traspasado a jurisdicción eclesiástica9 ${ }^{9}$ Aunque no tenemos evidencia directa, se puede asumir que la recaudación de este tributo competía a las autoridades locales después de haber recibido la

La Crónica del Rey Don Alfonso el Onceno (CRÓNICA) menciona que durante julio de 1343, el coste de una fanega de trigo era 30 maravedíes, pero después ascendió a la exhorbitante cuantía de 1.500 maravedíes debido a una severa escasez en Andalucía durante los meses de octubre y noviembre (caps. CCXCIX, CCCXII, CCCXXV).

4 En 1340, Alfonso XI contrató quince galeras genovesas para la guarda del Estrecho de Gibraltar. El precio de cada una era 800 florines (16.000 maravedíes), con excepción de la galera del almirante que costaba 1.500 florines (30.000 maravedíes), por mes más el bizcocho necesario para sustentar cada embarcación. El coste mensual de esta flota es aproximadamente 14.200 florines (284.000 maravedíes) (CRÓNICA, cap. CCXII). Ciertamente las embarcaciones castellanas costarían menos que las mercenarias extranjeras, ya que, por ejemplo, las galeras aragonesas presentes en el cerco de Algeciras costaban solamente 9.000 maravedíes cada una o 90.000 por mes (Cuenta de Juan Ferránez Muñoz, maestre del importe de armada, de Pedro IV, 1346, Archivo del Museo Naval de Madrid, Colección Sanz Barutell, Ser. Barcelona, MS. 355, fols. 213-19). Pero aunque las galeras y naos castellanas costasen menos, se puede observar con claridad el muy elevado coste de mantener una flota de más de noventa velas como la que asedió Algeciras en marzo de 1343 (CRÓNICA, cap. CCLXXXVII). En todas estas cifras monetarias utilizo el tipo de cambio delineado por Spufford et alii. (1986), 158.

5 Ladero Quesada (1993), 37-38.

6 CORTES (Cortes de Palencia, 1286), vol. 1, p. 96.

7 Ibid. (Cortes de Valladolid 1307, 1312), vol. 1, pp. 188-89, 212-13, 218.

8 Ibid. (Cortes de Valladolid, 1325), vol. 1, 384; Carta de Pedro I a su despensero mayor. (Valladolid, 28 de julio de 1352). Díaz Martín (1997-99), vol. 3, doc. 736, pp. 84-84.

9 Ladero Quesada (1993), 46. 
orden real. Los pecheros pagaban en moneda o con una acémila, y su contribución individual se determinaba a base del nivel de ingresos ${ }^{10}$.

Aunque en teoría este impuesto debía haber sido suficiente para abastecer a los ejércitos reales de suficientes bestias de carga, en la práctica esto era más complicado. En primer lugar, muchas localidades e individuos dentro del reino gozaban de exenciones concedidas por la Corona. La nobleza, especialmente los ricos hombres, estaban libres de esta obligación aunque seguramente la imponían sobre sus tierras para el uso de sus huestes. En otras instancias, había condiciones muy específicas de cuándo se podían recaudar acémilas. Por ejemplo, en algunos lugares solamente se proveían acémilas a una expedición si el rey estaba presente como líder, y en otros si la campaña estaba dirigida específicamente en contra de los musulmanes ${ }^{11}$. Debido al alto nivel de las operaciones militares durante su reinado, Alfonso se vio obligado a aumentar los niveles de acémilas y ordenar su recaudación incluso en áreas previamente exentas. En 1342 y 1343, suspendió la exención del obispo de Segovia para financiar el sitio de Algeciras $^{12}$. Los recaudadores reales bajo sus órdenes impusieron esta carga a las poblaciones del obispado de León, a pesar de que este último gozaba de libertad tributaria ${ }^{13}$. Sin embargo, si se tienen en cuenta los conflictos y dificultades relacionados con su recaudación, la conclusión más probable, es que cuando Alfonso impuso acémilas a diversas localidades, generalmente recibió todo, o una buena parte, de lo que deseaba. Para las distintas comunidades era preferible entregar bestias o dineros en vez de arriesgarse a provocar la ira del monarca.

El tributo de galera era la obligación impuesta sobre ciertos pueblos en la región de Cantabria de suministrar buques armados al monarca cuando éste los necesitase. Este impuesto existía desde finales del siglo XIII, cuando Santander, por ejemplo, debía proporcionar un nao y una galera cuando el rey estaba en campaña y necesitaba apoyo naval; la ciudad de Laredo, a cambio de estar libre de una serie de otros tributos, estaba obligada a entregar una galera de sesenta remos y sesenta hombres, armada y subvencionada por tres meses; de forma similar, Castro Urdiales, a cambio de estar exento de todos los impuestos reales, se comprometía a equipar una nao o galera que estuviese al servicio del rey por tres meses ${ }^{14}$. Después de 1344 , el puerto de Algeciras estaba obligado a armar y enviar dos galeras a Sevilla cuando se reuniese la flota real ${ }^{15}$. Es difícil determinar con exactitud la eficiencia de este tributo durante el reino de Alfonso ya que la gran mayoría de la documentación que ha llegado hasta nosotros se refiere a exenciones de dicha obligación ${ }^{16}$. Además, el monarca no podía depender exclusivamente de este insuficiente tributo para satisfacer sus exigencias navales, y en tiempo de guerra el

10 CORTES (Cortes de Valladolid, 1351), vol. 2, pp. 126-27, 130-31.

11 Carta del Rey D. Fernando, despachada en Cortes, por la cual manda que no se tomen acémilas de los vasallos del arzobispo de Toledo ni de los de su cabildo, no yendo el Rey en persona a la hueste y contra moros. (Valladolid, 15 de junio de 1307). Benavides (1860), vol. 2, doc. 385, pp. 565-66.

12 Privilegio real de Alfonso XI a Segovia reafirmando que Segovia paga 6.000 maravedíes anuales a cambio de exención tributaria de acémilas y fonsadera con la excepción de los años 1342 y 1343 . (Valladolid, 3 de noviembre de 1351). Díaz Martín (1997-99), vol. 2, doc. 532, pp. 266-69.

13 Alfonso XI manda al consejo de Mansilla que no tome prendas por fonsadera ni por el sueldo a los vasallos que el obispo de León tiene en sus aldeas de Payuelo, pues fue fallado por la audiencia real que, como vasallos del obispo, han de pagar acémilas de este año en los obispados de León y Astorga. (Real sobre Algeciras, 8 de julio de 1343). Martín Fuertes (1995), doc. 3081, p. 454.

14 Martínez Díez (1981), docs. 108, 328, 330, vol. 2, pp. 180-81, 567-70.

15 López De Ayala, Crónica del Rey Don Enrique, lib. 1, cap. VII.

16 Alfonso XI confirma un privilegio real de Fernando IV a Avilés que establecía que la ciudad estaba exenta de fonsadera y galera, excepto si el rey estuviera cercado o fuera a lid campal. (Madrid, 16 de agosto de 1329). Benito Ruano (1992), doc. 81, pp. 129-31. 
almirante mayor podría requisar el número necesario de embarcaciones ${ }^{17}$. El elevado coste de construir y armar buques hizo que el impuesto de galera y la requisa de embarcaciones siempre fuesen fuente de polémica entre el rey y las ciudades. Ni uno ni otras podían dar por sentado estas obligaciones, o la exención de ellas ${ }^{18}$.

La fonsadera, o pago monetario a la Corona en lugar de la prestación de servicio militar, sólo se debía imponer en tiempos de guerra. Todo parece indicar que las cuantías recaudadas se determinaban en base a lo establecido en el fuero de las diferentes localidades, lo que se negociase con las autoridades locales, y/o lo que se determinase en base a la recopilación de padrones locales sobre los ingresos y recursos de aquellos obligados a rendirla ${ }^{19}$. Aun cuando la Corona recaudase y utilizase una parte sustancial de los ingresos de este tributo, en época del reinado de Alfonso ya se había establecido la costumbre de permitir que la nobleza y caballeros o las Ordenes Militares recibiesen la fonsadera en vez de entregársela a los oficiales reales $^{20}$. Esta práctica seguramente hizo más eficiente la recaudación local de dicho impuesto, pero redujo drásticamente el control real sobre ella ${ }^{21}$. Sin embargo, Alfonso ordenó su recaudación en 1330, ${ }^{22} 1332,{ }^{23} 1340,{ }^{24} 1343-44$ para el sitio de Algeciras ${ }^{25}$ y $13499^{26}$. Para finales de su reinado, la evidencia demuestra que las áreas fuera del realengo todavía sujetas a este tributo estaban bajo jurisdicción eclesiástica y que debido al gran número de exenciones y los conflictos internos castellanos, las cuantías abonadas a la hacienda real se habían reducido consider-

17 Alfonso XI confirma una carta de Fernando IV a San Sebastián, ordenando que no se requisen más embarcaciones para la flota real. (Valladolid, 1318). Martínez Díez et alii. (1991), doc. 134, pp. 135-36.

18 Ladero Quesada (1993), pp. 45-46.

19 Alfonso XI, a demanda de los cogedores de la fonsadera del año 1330, manda al concejo y a los jueces y alcaldes de la ciudad de León y de Val de Torío que obliguen a pagar las cuantías de la fonsadera que se les han echado en los padrones a todos los que se niegan llamándose excusados de las iglesias, de los abadengos o hidalgos, a no ser que tengan los privilegios y cartas indicadas en la carta real de la recaudación (Segovia, 28/sept./1331). Martín Fuertes (1995), doc. 1989, p. 356.

20 Privilegio de Alfonso XI a la Orden de Calatrava. (Real sobre Gibraltar, 10 de agosto de 1349). Archivo Histórico Nacional (Madrid), Sec. Órdenes Militares, Cpta. 5, vol. 1, 44.

21 CORTES (Ayuntamiento de Carrión, 1317), vol. 1, p. 313 (Cortes de Medina del Campo, 1318), vol. 1, p 361, (Cortes de Madrid, 1329), vol. 1, p. 421. Privilegio de Alfonso XI concediendo al infante don Fadrique, maestre de Santiago, que en las villas y lugares de la dicha Orden, la fonsadera tan sólo se pague a la misma Orden. (Real sobre Gibraltar, 10 de agosto de 1349). AHN, Sec. Ordenes Militares, Cpta. 413, 56.

22 Carta de Alfonso XI a León. (1331), Martín Fuertes (1995), Op. cit.

23 Alfonso XI manda a los recaudadores de las fonsaderas en el reino de León que guarden al concejo de León, durante los próximos seis años, el encabezamiento que tienen para el pago de la fonsadera; y que no se la exijan por padrón. (Burgos, 10 de agosto de 1332). Martín Fuertes (1998), doc. 92, pp. 134-35.

24 López Ferrández, de la cámara del rey, comunica al concejo de Cuéllar que pague el importe de la fonsadera a Juan González de Roa, ballestero del rey, y a Ferrán Pérez de Saldaña, o a cualquier de ellos, o a quien éstos designasen. (20 de febrero de 1340). Ubieto Arteta (1961), doc. 93, pp. 193-94. Alfonso XI manda al concejo de León que, por cuanto va a la frontera para la guerra con los moros, le paguen la fonsadera de este año todos los de la ciudad y su término que están obligados a ir en fonsado, con las excepciones expresadas y de acuerdo con las ordenanzas y cuantías que expone detalladamente, nombrando cogedor de ella a Sancho Díez de Sahagún. (Madrid, 25 de enero de 1340). Martín Fuertes (1995), doc. 3058, pp. 427-30.

25 Carta de Alfonso XI que asegura a quienes arrendaren de don Yuzaf el Leví la fonsadera del año que comenzara en marzo de 1344, que mandaba a coger en el año la data por adelantado en León y sus aldeas (Real sobre Algeciras, septiembre de 1343); Carta de Alfonso XI, a instancia de don Yuzaf el Leví, al concejo de León para hacerle saber que había ordenado pesquisa sobre los empadronadores de la fonsadera (Real sobre Algeciras, septiembre de 1343). Martín Fuertes (1998), docs. 134-35, pp. 186-87. Carta de Alfonso XI a todos los lugares abadengos del obispo de Burgos para que paguen fonsadera y ordena cómo debe ser el proceso de recaudación (Real sobre Algeciras, febrero de 1343). Arch. Mun. Covarrubias, leg. 7, no 29; Serrano (1907), doc. 164, pp. 195-97.

26 Provisión de Pedro I a los recaudadores de la fonsadera ordenándoles que si la ciudad de León no pagó cuando Alfonso XI estuvo en el cerco de Algeciras, tampoco se les exija la que el mismo rey mandó coger en 1349, cuanto estaba en el cerco de Gibraltar. (Valladolid, 14 de mayo de 1351). DÍAZ Martín (1997-99), doc. 104, vol. 1, pp. 140-41. 
ablemente ${ }^{27}$. Sin embargo, la fonsadera siempre fue un recurso importante para la Corona, si acaso indirectamente, ya que en vez de simplemente caer en desuso este tributo se recaudaba a nivel local, fuese por parte de la nobleza o los concejos urbanos, y se utilizó para financiar la participación de las huestes locales en las campañas militares reales ${ }^{28}$.

La hacienda real también se beneficiaba de la recaudación del quinto real sobre todo el botín conseguido en todas las cabalgadas y otras operaciones en contra de los musulmanes, ya fuesen bienes, dineros o cautivos ${ }^{29}$. La propia naturaleza del quinto, un porcentaje del botín apresado, siempre hizo imposible calcular de antemano su monto. No obstante, Alfonso, además de beneficiarse directamente de esta fuente de ingresos, utilizó el quinto como incentivo para que las poblaciones fronterizas de Andalucía se armasen y atacasen a las vecinas localidades musulmanas, ya fuera por medio de la entrega de parte del monto final, o con la concesión de exenciones de su colecta a individuos, ciudades o grupos ${ }^{30}$. En 1333, Alfonso reafirmó que los vecinos de Murcia tenían por derecho la obligación de pagar un séptimo en vez del usual quinto, pero no desistió por ello de recaudarlo ${ }^{31}$. El año siguiente, el monarca intervino en una disputa sobre cómo debía dividirse el botín de unas recientes acciones militares. En concreto, se trataba de determinar si unos caballeros cristianos, después de haberse adentrado en territorio musulmán, derrotado a sus enemigos y recuperado algunos ganados robados, tenían el derecho de apropiarse de las bestias o si estaban obligados a devolverlas a sus dueños originales. Alfonso confirmó el fallo de las autoridades locales a favor de los caballeros, tomando como razón que las bestias les pertenecían ya que fueron recuperadas de territorio enemigo por sus propios esfuerzos y $\operatorname{costos}^{32}$. En otras ocasiones, el rey podía asignar las cuantías del quinto real para subvencionar los gastos locales de defensa, como lo hizo cuando puso el castillo de Tíscar bajo la autoridad de Úbeda. ${ }^{33} \mathrm{~A}$ pesar de que esta fuente de ingresos no era tan significativa o fiable como otras, la atención prestada por la Corona a su administración demuestra que continuó siendo un recurso importante durante el reinado de Alfonso.

Otro recurso fiscal ligado específicamente a la guerra fueron las parias, en uso desde finales del siglo XIII, que rendía el emirato de Granada al monarca castellano durante los períodos de tregua entre ambos. En la práctica, el emir de Granada aceptaba ser vasallo del rey de Castilla a cambio de una autonomía limitada para su emirato. Pese a todo, y aunque las parias podían ser sustanciales y se entregaban todos los años, el monto total era especialmente impredecible, pues nunca faltaban circunstancias - guerra, debilidad de Castilla o falta de voluntad granadina - para que se suspendiese su pago. La guerra civil en Castilla durante su minoría y la guerra abierta contra Granada en los primeros cinco años de Alfonso como rey adulto

27 Álvarez Borge (1987), 108.

28 Privilegio de Alfonso XI a los caballeros de Cuenca (Cuéllar, 20 de mayo de 1322). Cit. Cabañas González (1980), 37.

29 PARTIDAS, II, Tít. 26, Ley 2.

30 Carta plomada de Alfonso XI a todas las autoridades y concejos de sus reinos, confirmando la franqueza otorgada por Alfonso X a los armadores de Cartagena, Guardamar, Alicante y Murcia. (Tordesillas 24 de junio de 1347). Veas Arteseros (1997), doc. 412, p. 469.

31 Provisión real de Alfonso XI a don Mayr Aben Mudur, recaudador del almojarifazgo y quinto de las cabalgadas del reino de Murcia, ordenándole que respetase las franquicias de los vecinos de Murcia. (Valladolid, 27 de febrero de 1333); Albalá de Alfonso XI al concejo de Murcia, notificando que los derechos de las cabalgadas debían ser pagados al nuevo arrendador de la renta, don Haym Aben Mudur. (Valladolid, 2 de mayo de 1333). Veas Arteseros (1997), docs. 236, 241, pp. 272-74, 278-79.

32 Mandato real de Alfonso XI a los alcaldes de Murcia, ordenándoles que respetasen la sentencia dada por Bernat Solzina, en el pleito por el reparto del botín recuperado de unos moros de Vélez que habían asaltado Pliego. (Burgos, 2 de mayo de 1334). Veas Arteseros (1997), doc. 270, pp. 312-13.

33 Alfonso XI concede al concejo de Úbeda el castillo de Tíscar. (Valladolid, 28 de noviembre de 1335). Arch. mun. Úbeda, Cpta. 4, nº 8. Carriazo Arroquia (1975), doc. 24, pp. 40-44. 
aseguraron que los musulmanes no enviasen cuantía alguna a las arcas reales. Terminados los combates y con una nueva tregua firmada con Muhammad IV (1325-33) en 1331, Alfonso podía contar con unas parias anuales de 12.000 doblas (246.000 maravedíes) ${ }^{34}$. Sin embargo, dos años después, la reanudación del conflicto abierto entre ambas partes, hizo que este acuerdo quedara sin efecto. La suma de 12.000 doblas anuales se institucionalizó durante las últimas décadas del reinado de Alfonso, como se puede ver en los acuerdos firmados después de la fallida operación en Gibraltar de $1333^{35}$ y la captura de Algeciras en $1344^{36}$.

No es difícil suponer que, con los ya mencionados impuestos y otros ingresos regulares, ${ }^{37}$ la Corona dispondría de suficientes recursos para llevar a cabo todos sus objetivos militares. Sin embargo, durante el reinado de Alfonso, la combinación del gran número de exenciones fiscales previamente concedidas a individuos, ciudades e instituciones castellanas, la reducción en términos reales de los impuestos debido a la inflación y la creciente depresión económica, condición exacerbada por la larga y difícil minoría, los graves e interminables conflictos entre la nobleza y el monarca, y las numerosas guerras fronterizas, aseguraron que la situación fiscal de la hacienda real siempre fuese precaria. En el ayuntamiento de Carrión (1317), para tomarlo como ejemplo, se determinó que el monto de los ingresos reales eran 1,6 millones de maravedíes anuales, pero los gastos ordinarios relacionados con la administración del reino ascendían a 9,6 millones. A pesar de que se aprobaron nuevos impuestos para solventar la crisis, es probable que su monto total no llegara a más de cinco millones de maravedíes, lo cual engendró un abultado déficit presupuestario ${ }^{38}$. Se puede ver que desde muy temprano y en todo momento, Alfonso tuvo que enfrentarse a grandes dificultades fiscales para gobernar y poner en práctica sus programas políticos y militares ${ }^{39}$.

¿Cómo pudo Alfonso superar estas serias limitaciones fiscales para no sólo resistir tantos ataques sino también triunfar sobre todos sus enemigos? La respuesta reside en la astuta explotación de fuentes de ingresos extraordinarios como las monedas foreras, servicios o ayudas, alcabalas, apropiación de recursos eclesiásticos, empréstitos, la apropiación de recursos locales o la eliminación de exenciones fiscales preexistentes, y en algunos casos la venta de algunas partes del fisco real. Este monarca, con algunos momentos de verdadero apuro, siempre pudo acumular los recursos monetarios necesarios para subvencionar sus ambiciones militares, aun-

34 Carta plomada partida, notificando a todos sus reinos la tregua pactada con el rey de Granada. (Sevilla, 19 de febrero de1331). Veas Arteseros (1997), doc. 168, pp. 188-92.

35 Tratado de paz entre Yūsuf I ibn Abi-l-Walid Isma'il ibn Faray ibn Nāsr de Granada y Alfonso IV de Aragón adhiriéndose a la paz concertada entre el Rey de Fez Abū l-hasan y Alfonso XI de Castilla. (julio de 1333). Alarcón Y Santón et alii. (1940), doc. 30, pp. 61-63.

36 Capitulación de Algeciras y entrada de Alfonso XI en ella. (Algeciras, 26 de marzo de 1344); Notificación de Don Juan Manuel a Pedro IV de la capitulación de Algeciras. (Algeciras, 22 de abril de 1344); Notificación a los de Murcia de la paz pactada entre Alfonso XI y el Sultán de Marruecos y el Rey de Granada. (Sevilla, 6 de mayo de 1344). Giménez Soler (1932), docs. 572-74, pp. 642-43.

37 Entre éstos estaban la martiniega, el montazgo, los pagos de parte de las juderías y aljamas, los pedidos, los almojarifazgos y las regalías.

38 CRÓNICA, cap. X; Grassotti (1990), 3437.

39 En particular, hay que mencionar su reforma de las soldadas reales promulgada en el ayuntamiento de Burgos (1338), en la cual se estipuló que todos los nobles de los reinos del norte de Castilla que recibiesen soldadas de parte de la Corona debían reservar dos terceras partes para el reclutamiento de caballería e infantería. Por cada 1.100 maravedíes recibidos, se tenía que reclutar a un caballero y dos soldados de infantería, uno armado con lanza y el otro con ballesta. La alta nobleza debía además incluir un caballero con armadura pesada, que contaba como 1.300 maravedíes en contra del monto de la soldada, dentro de cada diez caballeros reclutados. Además se espeficaba el salario de los soldados de a pie y los castigos potenciales a los que no siguiesen las nuevas pautas. Ciertamente, esta reorganización permitió que la monarquía ejerciera un mayor control sobre el reclutamiento de los ejércitos, pero para su implementación y administración requería de un mayor gasto de parte de la hacienda real. CORTES (Ayuntamiento de Burgos, 1338), vol. 1, pp. 450-53. 
que es importante mencionar que una de las consecuencias fue el aumento considerable de la carga fiscal, ya pesada, sobre sus súbditos.

Aunque lo hubiera deseado, sin embargo, Alfonso no podía imponer arbitrariamente nuevos tributos sobre sus reinos, sino que debía convocar las cortes o, por lo menos, un ayuntamiento o reunión parcial. Todos ellos servían al monarca para exigir la imposición de nuevos impuestos y explicar por qué eran necesarios; para los convocados, eran la ocasión de presentar quejas y súplicas al rey y también de negociar la cuantía global antes de dar su aprobación a cualquier tributo extraordinario ${ }^{40}$.

Las monedas foreras eran uno de los más importantes impuestos reales, y se imponían sobre el reino a cambio de que el rey no alterase la composición o valor de las monedas castellanas. Aunque la devaluación de la moneda era un mecanismo utilizado por la Corona para recaudar fondos, su uso siempre estimulaba la inflación en todo el reino. Ya hacia finales del siglo XIII, la moneda forera se recaudaba cada siete años sin necesidad del consentimiento de los representantes del reino. ${ }^{41}$ Por ejemplo, Alfonso recolectó monedas foreras en $1318^{42} \mathrm{y}$ $1325^{43}$. Pero la moneda forera también podía derramarse de forma extraordinaria, pero sólo con el asentimiento previo y específico de las cortes. De este modo, Alfonso pudo recaudar monedas en $1329,{ }^{44} 1336,{ }^{45} 1341-42^{46}$ y 1343 , la última concedida para prevenir la inflación que podría ocurrir a consecuencia de una devaluación de la moneda que el monarca había ordenado con la acuñación de monedas de menor valor ${ }^{47}$. En 1349, Alfonso hizo los arreglos necesarios para una nueva colecta extraordinaria de moneda para sufragar los gastos del sitio de Gibraltar pero falleció antes de que se pudiese recolectar en su totalidad ${ }^{48}$.

La moneda forera era muy valiosa ya que se imponía por cabeza, en proporción del patrimonio individual, y había relativamente pocas exenciones en comparación con otros tributos $^{49}$. En 1294, se recaudaba a razón de 8 maravedíes por pechero en Castilla, Extremadura y Andalucía, y 6 en León. Estas cuantías no cambiaron ya que se confirmaron en 1350 en una carta de Pedro I (1350-69) a Murcia en la que se estableció que cualquier pechero con ingresos de 60 maravedíes tenía que pagar moneda forera a razón de 8 maravedíes por colecta ${ }^{50}$. Desafortunadamente no contamos con cifras exactas, ni de las cuantías locales ni globales, de las diferentes colectas de este tributo. El profesor Ladero Quesada ha estimado que incluso

40 O’callaghan, J. F. (1989), 130-32.

41 Alvarez Borge (1987), 106.

42 CRÓNICA, cap. XII; Carta de Alfonso XI y sus tutores en respuesta a los caballeros, escuderos, dueñas y doncellas. (Medina del Campo, 10 de septiembre de 1318). Arch. Mun. Alba de Tormes, doc. F2. Barrios García (1982), doc. 29, pp. 97-99.

43 Carta de Alfonso XI al concejo de Murcia con cuaderno de las cortes de Valladolid. (Valladolid, 12 de diciembre de 1325). Veas Arteseros, (1997), doc. 53, p. 64.

${ }_{44}$ CRÓNICA, cap. LXXX; Traslado de carta de Alfonso XI en que ordena que paguen moneda forera todos los vasallos de sus reinos. (Valladolid, 12 de diciembre de 1329). AHN, Sec. Clero, Cpta. 506, doc. 4. González Crespo (1985), doc. 146, pp. 273-76; Provisión real de Alfonso XI a los recaudadores de moneda forera en Murcia. (Villareal, 30 de junio de 1330). Op cit., doc. 152, pp. 172-73.

45 CRÓNICA, cap. CLV; Albalá de Alfonso XI al concejo de Murcia. (Burgos, 22 de abril de 1336), Provisión real de Alfonso XI a los recaudadores de la moneda en Murcia. (Real sobre Lerma, 15 de octubre de 1336). Op cit., docs. 308, 327, pp. 354, 371-72.

46 Mandato real de Alfonso XI al concejo de Murcia. (Madrid, 25 de enero de 1341), Provisión real de Alfonso XI a los recaudadores de la moneda forera. (Ávila 20 de abril de 1342), Provisión real de Alfonso XI a los recaudadores de la moneda forera en la ciudad de Murcia. (Segovia, 29 de abril de 1342). Op cit., docs. 384, 393, 395, pp. 436-37, 446-47, 448.

47 CRÓNICA, cap. CCLXXXII.

48 Provisión de Alfonso XI a los concejos de Murcia. (Real de Gibraltar, 10 de agosto de 1349). Op. cit., doc. 436, pp. 498-501.

49 Álvarez Borge (1987), 106

50 Carta de Pedro I al obispado de Cartagena y el reino de Murcia, especificando las condiciones que tenían que pagarle la moneda forera.» (Sevilla, septiembre de 1350). Molina Molina (1978), doc. 15, pp. 17-20. 
durante la difícil minoría de Alfonso cada moneda podía rendir hasta un millón de maravedíes, bastante menos que los 1.500 .000 que se habían alcanzado durante el reinado de Sancho IV $(1284-95)^{51}$. Sin embargo, hay que tener en cuenta que no todas las monedas foreras se recaudaban en todo el reino. La moneda de 1343 se impuso con el consentimiento de los representantes de las ciudades que habían enviado tropas al cerco de Algeciras y su colecta se efectuó en estos mismos pueblos y en las áreas contiguas. Aunque elevadas, no parece que sus cuantías pudiesen ascender al mismo nivel que las aprobadas por las cortes para todo el reino.

De igual o mayor importancia para Alfonso fueron los servicios o ayudas, los cuales eran impuestos extraordinarios aprobados en las cortes o ayuntamientos. El vocablo «servicio» se ve por primera vez a mediados del siglo XIII. En general, se trataba de un impuesto sobre bienes muebles, excepto si se designaba como el equivalente a una moneda forera en cuyo caso era un impuesto per cápita ${ }^{52}$. Los tesoreros reales ciertamente tenían una predilección por esta clase de gravamen ya que no estaba bajo la jurisdicción de los fueros tradicionales, abarcaba a la gran mayoría de Castilla, ${ }^{53}$ y las cuantías a recaudar nunca estaban establecidas sino que se negociaban periódicamente ${ }^{54}$.

Durante el reinado de Fernando IV, los gravámenes extraordinarios ocurrían con suficiente frecuencia como para poder considerarlos habituales. Entre 1300 y 1312, se recaudaron servicios por lo menos ocho veces para subvencionar la política doméstica y militar de la Corona ${ }^{55}$. Alfonso vino a depender aún más de los servicios extraordinarios ya que se recaudaron en 1314 en las cortes de Valladolid y Medina del Campo (cinco servicios); ${ }^{56} 1315$ en Burgos (tres ayudas); ${ }^{57} 1316$ para el Infante Pedro (un servicio de 1.000 .000 mrs); ${ }^{58} 1317$ en Carrión (cinco servicios); ${ }^{59} 1318$ para financiar las operaciones militares en la frontera, incluyendo la fallida expedición a la Vega de Granada, (cinco servicios); 601320 (siete y medio servicios para el Infante Juan Manuel de parte de los que lo tomaron como tutor y seis para los que reconocían al Infante Felipe); ${ }^{61} 1325$ (cinco servicios para el Infante Juan de parte de los que lo tomaron como

51 Ladero Quesada (1993), 223.

52 O’callaghan, J. F. (1989), 135. En ciertos casos algunas localidades acordaban pagar una cuantía fija a la Corona por servicio a cambio de que los oficiales locales o reales no hiciesen pesquisa y padrones nuevos de pecheros, como se puede observar en Béjar, donde Alfonso XI exime de pago de servicios a sus habitantes, fijando que los habitantes de su término han de pagar 3.000 maravedís por cada servicio. (3 de septiembre de 1322). Arch. Mun. de Béjar, Sec. 1, Leg. 1, $n^{\circ}$ 15. García Barrios, A. et alii. (1986), doc. 30, pp. 65-66.

53 En el Libro becerro de las behetrías se puede ver que el 89\% de los lugares incluidos estaban sujetos a los servicios, o sea que era un tributo de alcance casi universal. No parecería ilógico asumir que las localidades en Andalucía, Extremadura y Galicia estarían sujetas a porcentajes similares.

54 Ladero Quesada (1993), 57-58.

55 CRÓNICA DEL REY DON FERNANDO IV. caps. VIII, X, XIII-XVI, XX; Privilegio de Fernando IV concediendo al arzobispo de Toledo y su cabildo exención de la mitad de los servicios con que habían contribuido sus vasallos para los gastos de la guerra. (Valladolid, 12 de noviembre de 1302). Carta de Fernando IV al arzobispado de Toledo pidiendo un sexto servicio para la flota del mar y la defensa de Gibraltar y Tarifa. (Toledo, 15 de julio de 1312). Benavides (1860), docs. 224, 583, vol. 2, pp. 336-38, 862.

56 Carta de Alfonso XI al arzobispo de Toledo eximiéndole de una parte del total por los servicios votados en las cortes en Valladolid. (Valladolid, 10 de agosto de 1314). AHN, Sec. Clero, Cpta. 3026, doc. 15. González Crespo (1985), doc. 14, pp. 48-49. Carta de Alfonso XI a los recaudadores de la merindad de Candemuñó y del Infantado de Covarrubias. (Dueñas, 28 de abril de 1314). Pereda Llarena (1980), doc. 469, vol. 2, pp. 319-21.

57 CRÓNICA, cap. VIII.

58 Ibid.

59 Ibid., cap. X.

60 Carta de Alfonso XI y sus tutores en respuesta a los caballeros, escuderos, dueñas y doncellas. (Medina del Campo, 10 de septiembre de 1318). Arch. Mun. Alba de Tormes, doc. F2. García Barrios et alii. (1982): doc. 29, pp. 97-99. Carta de Alfonso XI al maestre de la Orden de Calatrava. (Valladolid, 26 de octubre de 1318). AHN, Sec. Órdenes Militares, Cpta 429, doc. 191; CRÓNICA, cap. XII.

61 CRÓNICA, cap. XXVII. 
tutor); 621324 (cinco servicios recaudados por Juan Manuel en los territorios bajo su dominio); ${ }^{63}$ 1325 cuando Alfonso asumió las riendas del poder como adulto (cinco servicios); ${ }^{64} 1329$ para subvencionar la campaña contra de los musulmanes del año siguiente (cuatro ayudas); 651332 para la defensa de la frontera y su coronación en Santiago de Compostela (un servicio íntegro y cuatro servicios recaudados en los territorios de la Orden de Santiago en Toledo y Cuenca); ${ }^{66}$ 1336 (cinco servicios) ${ }^{67}$ y 1337 (un servicio parcial) ${ }^{68}$ para ayudar contra las rebeliones de Juan Núñez de Lara y Juan Manuel; 1339, servicio aprobado en el ayuntamiento de Madrid en respuesta a las agresiones de los benimerines en Andalucía; 691340 servicio reducido aprobado en un ayuntamiento en Llerena, específicamente para vigilar contra posibles incursiones desde Marruecos; $;^{70}$ y en 1349 se derramaron dos servicios para sufragar los gastos de la segunda campaña de Alfonso para la conquista de Gibraltar ${ }^{71}$.

Desafortunadamente, la documentación del siglo XIV, necesaria para determinar con exactitud las colectas y montos globales de los servicios extraordinarios, no ha llegado hasta nuestros días. Es más, no tenemos información directa sobre los porcentajes de exacción con la excepción del servicio de Juan Manuel en 1312, recaudado a razón de seis por ciento (60 de cada 1.000 maravedíes de patrimonio en bienes muebles e inmuebles) con exención fiscal a todo el que tuviese $8 \mathrm{mrs}$ o menos de ingresos ${ }^{72}$. Cabe la posibilidad de que la falta de evidencia específica indique que no había un tipo de gravamen estándar en cuanto a los servicios ${ }^{73}$.

Sin embargo, todo apunta a que las cuantías recaudadas en los servicios fueron sustanciales. En 1316, el Infante Pedro fue el beneficiario de un servicio que ascendía a un cuento o 1.000.000 de maravedíes. En el ya mencionado ayuntamiento de Carrión (1317), la hacienda real declaró que sus ingresos eran sólo 1.600 .000 maravedíes, pero sus gastos ascendían a 9.600.000. Aunque la veracidad de estas cifras es dudosa debido a la carencia de pruebas documentales, se puede observar que las rentas reales habían disminuido a niveles intolerables, por cuya razón se le concedieron al rey y a sus tutores cinco servicios. Si con ellos se hubiera reducido por completo el déficit presupuestario, la colecta habría totalizado 8.000.000 maravedíes, o sea, cada servicio habría rendido 1.600.000. En realidad, la inestabilidad del reino durante la minoría de Alfonso probablemente limitó las cuantías que se podían recaudar a tal vez 500.000

62 Ibid. cap. CCIX.

63 Ibid. cap. XXXI.

64 Carta de Alfonso XI a todos los lugares de la Sacada de Mayorga, con motivo de los servicios votados en las Cortes de Valladolid, ordenando que paguen lo que les corresponde y se ha estipulado. (Valladolid, 17 de febrero de 1326). AHN, Sec. Clero, Cpta. 3429, doc. 15. González Crespo (1985), doc. 91, pp. 146-49; CRÓNICA cap. XL.

65 Traslado de carta de Alfonso XI en que ordena que paguen moneda forera todos los vasallos de sus reinos (Valladolid, 12 de diciembre de 1329); AHN, Sec. Clero, Cpta. 506, doc. 4; González Crespo (1985), doc. 146, pp. 273-76; CRÓNICA, cap. LXXX.

66 Carta de Alfonso XI al maestre de la Orden de Santiago. (Valladolid, 10 de marzo de 1332). Real Academia de la Historia (Madrid), Col. Salazar y Castro, MS. M-128, fols. 303rev.-305anv. Cit. Grassotti (1990), 3445-46.

67 Carta de Alfonso XI al arzobispo de Toledo sobre la recaudación de cuatro servicios. (Real sobre Lerma, 5 de diciembre de 1336). AHN, Sec. Clero, Cpta. 3028, doc. 3; González Crespo (1985), doc. 242, pp. 414-15. CRÓNICA, 273, chap. 154.

68 Provisión de Alfonso XI a los recaudadores del servicio en Montiel. (Mérida, 20 de diciembre de 1337). Provisión de Alfonso XI a los recaudadores del servicio de la Orden de Santiago. (Burgos, 15 de abril de 1338). Veas Arteseros (1997): docs. 354, 358, pp. 398-99, 402-03.

69 CRÓNICA, cap. CXCVI.

70 Ibid., cap. CCLIV.

71 Provisión de Alfonso XI a todas las autoridades y concejos del reino de Murcia, notificando la recaudación de una moneda y dos servicios para la guerra de Granada. (Real sobre Gibraltar 10 de agosto de 1349). Provisión real de Alfonso XI a todos los concejos del reino de Murcia. (Real sobre Gibraltar, 15 de octubre de 1349). Veas Arteseros (1997): docs. 436, 440, pp. 498-501, 504-07; CORTES (Cortes de Valladolid, 1351), vol. 2, p. 63.

72 CRÓNICA, cap. XXVII.

73 O'callaghan (1993), 143. 
maravedíes por servicio. ${ }^{74}$ Aunque es mera conjetura, si se asume que cada servicio, y fueron muchos (ver tabla 1 en el apéndice), podría rendir entre medio y un millón de maravedíes, entonces las cuantías globales ingresadas por los cogedores de Alfonso fluctuarían entre 12-24 millones de maravedíes. Estos dineros, junto con las monedas extraordinarias, se utilizaron casi exclusivamente para gastos militares como la defensa de la frontera, incursiones en territorio enemigo, y la conquista de plazas musulmanas. En realidad, teniendo sólo en cuenta los fondos potenciales que se podrían recaudar mediante los servicios extraordinarios, se puede ver que éstos eran indispensables para la hacienda real de Alfonso.

Las constantes exigencias fiscales de sus ambiciones militares obligaron a Alfonso a buscar nuevas fuentes de ingresos más allá de las monedas y servicios. Una de sus iniciativas fiscales más importantes fue la expansión de la alcabala, el impuesto de un cinco por ciento sobre las ventas ya establecido desde el siglo anterior ${ }^{75}$. La alcabala fue muy útil porque era un impuesto sobre el comercio y, al igual que las monedas y servicios, no caía bajo la autoridad de los fueros, con lo que la Corona tenía mucho más control sobre su colecta y explotación. Durante el reinado de Alfonso, a pesar de este tributo era teóricamente una veintena parte, se recaudó a razón de 3,3 por ciento ${ }^{76}$.

Aun sin tener cifras exactas, este mecanismo debió haber ingresado cuantías sustanciales en la hacienda real. En 1333, Alfonso impuso las alcabalas en las regiones andaluzas para financiar la defensa de la frontera y el reclutamiento de 3.000 caballeros adicionales para servir en los diversos puestos fronterizos ${ }^{77}$. La Corona reimplantó este gravamen en 1338, destinando parte de los ingresos al mantenimiento de castillos y fortificaciones locales ${ }^{78}$. Cuando llegó el momento de la campaña de Algeciras, Alfonso implementó la primera alcabala a nivel global en Castilla en $1342^{79}$. Tres años después, logró que el ayuntamiento en Burgos consintiera a que se recaudara nuevamente durante los seis años siguientes ${ }^{80}$.

Alfonso también se benefició de los considerables recursos eclesiásticos de Castilla, en particular cuando el enemigo eran los musulmanes. Aunque los impuestos eclesiásticos se recaudaban a nivel local, todo monarca estaba obligado a obtener permiso de la Santa Sede antes de apropiarse de cualquier ingreso de la Iglesia. En la práctica, los retrasos rutinarios, pero intolerables, causados por los problemas de las distancias y las comunicaciones, las exigencias diplomáticas y protocolarias, y los procedimientos burocráticos de la Corona, los obispados y el Papado, llevó a los reyes de Castilla a apropiarse, o a tratar de hacerlo, de dineros eclesiásticos antes de recibir la aprobación de la Santa Sede. Sin embargo, e incluso teniendo en cuenta las disputas entre la Corona y el Obispo de Roma, los monarcas castellanos casi siempre pudieron contar con el uso de la riquezas de la Iglesia castellana. Estos recursos eran variados, pero el más importante era la bula de cruzada que, además de ayudar en las áreas del prestigio y del reclutamiento de tropas, permitía a Alfonso el uso de ciertas rentas eclesiásticas

74 Grassotti (1990), 3437.

75 Moxó (1963), 33, 39.

76 Ladero Quesada (1993), 189.

77 CRÓNICA, cap. CXXVIII; Provisión real al concejo de Murcia. (Sevilla, 23 de noviembre de 1333). Veas Arteseros (1997): doc. 258, pp. 294-96.

78 Provisión de Alfonso XI a los recaudadores de alcabalas en Murcia y Lorca ordenándoles que entregasen 80.000 maravedíes a Gonzalo Rodríguez de Avilés. (Sigüenza, 25 de julio de 1338). Op. cit., doc. 371, p. 422; Carta de Alfonso XI a los recaudadores de alcabalas de Ubeda que den $3.000 \mathrm{mrs}$. a la ciudad para las labores de Tíscar, Quesada y Albanchez. (15 de septiembre de 1338). Rodríguez Molina, (1994), doc. 67, p. 188.

79 CRÓNICA, cap. CCLXII.

80 CORTES (Ayuntamiento de Burgos, 1345), Vol. 1, pp. 488-89; Cuaderno real de Alfonso XI a todos los concejos de Murcia notificando el ordenamiento de las alcabalas. (Alcalá de Henares, 2 de febrero de 1348). Veas Arteseros (1997): doc. 424, vol. 6, pp. 482-84; Cuaderno de alcabala para recaudar en Murcia. (Sevilla, 18 de enero de 1351). Molina Molina (1978), vol. 7, doc. 19, pp. 23-24. 
en adición de las colectas hechas durante la predicación de dicha cruzada ${ }^{81}$. Durante su reinado, la Corona recibió bulas de cruzada en $1317,{ }^{82} 1319,{ }^{83} 1329,{ }^{84} 1340,{ }^{85}$ y $1342^{86}$. Todas estas campañas fueron contra ejércitos, plazas o fortificaciones granadinas o marroquíes, al contrario que la entrada castellana en Navarra (1335), el conflicto fronterizo contra Portugal (1336-38), o la pacificación de la nobleza del reino.

Tanto esmero en asegurar las bulas de cruzada se entiende al saber que los ingresos eclesiásticos más codiciados por la monarquía, eran las tercias reales, equivalentes a las dos novenas partes del diezmo eclesiástico, específicamente destinadas a la construcción y conservación de los diversos edificios religiosos en Castilla, y las décimas, que consistían en el diez por ciento de todas las rentas eclesiásticas ${ }^{87}$. Durante el reinado de Alfonso, las tercias reales fueron concedidas al Infante Pedro en 1317 para financiar su expedición contra Granada, ${ }^{88}$ y luego en $1328-32,{ }^{89} 1340,{ }^{90} 1343^{91} \mathrm{y} 1349^{92}$. Las décimas fueron concedidas en $1317,{ }^{93} 1328,{ }^{94} 1340^{95} \mathrm{y}$ $1343^{96}$. No existe documentación suficiente para determinar las cuantías globales de la colectas de las tercias y décimas. Sin embargo, éstas serían elevadas. La concesión al Infante Pedro en

81 Hay pocas referencias en cuanto a las cuantías recaudadas durante la predicación de las distintas cruzadas, lo cual hace muy difícil determinar su utilidad. (Ladero Quesada [1993], 207, 209). No obstante, en un documento de 1319, García de Sotocueva y Sancho Ochoa de Baracaldo, cogedores de la cruzada de los Infantes Pedro y Juan, afirman que recibieron de la ciudad de Guetaria 17.130 esterlines coronados para la cruzada. ( Martínez Díez, G. et alii. [1991], doc. 135, pp. 136-37). Dependiendo del valor de los coronados — entre 1.713 y 2.855 maravedíes si fueron coronados acuñados durante el reinado de Sancho IV o Fernando IV (Gil Farres [1976], pp. 343-44), ó entre 8.780 y 10.547 maravedíes si se refiere a monedas de plata inglesas o francesas (Hamilton, Earl J. [1936], 140-41) - la contribución monetaria de esta urbe ciertamente no fue insignificante. Es más, si se tiene en cuenta que éste era el monto de sólo una localidad y que la cruzada se predicaría en cientos de lugares, se puede ver que la predicación de por sí rendía frutos financieros no desdeñables.

82 Goñí Gaztambide (1958), 285.

83 GRAN CRÓNICA, cap. XIX.

84 Goñí Gaztambide (1958), 299.

85 Epistola ad Benedictus XII pro Alphonso, regi Castellae et Legionis, conceditur ut per certos archiepiscopos et episcopus praedicteur Crux in regnis, comitatibus et terris ... conceditur ad trienium decima omnium reddituum ecclesiasticorum regnortum et comitatuum praedictorum sub certis modificationibus ... (Aviñón, 7 de marzo de 1340). Reg. Vat., 128, n 14. Vidal (1902), doc. 8103, p. 278; Carta de Fernán García de Areilza, recaudador de la Cruzada, al obispo y al arcediano de Calahorra para que entreguen el importe recaudado en Navarra y en el obispado de Calahorra. (Madrid, 5 de marzo de 1341). Martínez Díez, G. et alii. (1991), doc. 214, pp. 227-28.

86 Bula de Clemente VI a Alfonso XI (22 de octubre de 1343). Serrano (1912), doc. 7, p. 33.

87 Torremocha Silva (1994), 59; Ladero Quesada (1993), 191, 203-05.

88 CRÓNICA, cap. XI.

89 Mandato de Juan XXII que encarga al arzobispo de Sevilla y a los obispos de Córdoba y Jaén que, en calidad de colectores y por medio de subcolectores, reclamen de todas las personas eclesiásticas y entreguen al rey Alfonso XI, en la forma y con las condiciones que se expresan, la décima de todas las rentas eclesiásticas de los reinos de Castilla y León y las dos partes de la tercia de las décimas que solían reservarse para las fábricas de las iglesias, como subsidios para hacer la guerra contra los sarracenos del reino de Granada, enemigos de la Cruz, y contra los que vienen en su auxilio. (Aviñón, 8 de abril de 1331). Martín Fuertes (1995), doc. 2987, pp. 354-55.

90 Epistola ad Bendictus XII de approbatione indictionis Cruciatae et impositione decame pro bello contra reges Granatae et de Benamarin, aliosque Sarracenos ... (Aviñón, 10 de mayo de 1340). Reg. Vat. A.A. Instr. Vidal (1902), doc. 8355, p. 306.

91 Alfonso XI, regi castellae, scribitur ut ratificatio conditionum habitarum pro concessione decimarum et duabus partibus decimarum per litteras regias extra tempus termini ipsi imposit valeat ac si facta fuisset infra ... (Aviñón, 22 de octubre de 1343). Serrano (1912), doc. 7, p. 33.

92 Provisión de Alfonso XI a las autoridades y concejos del obispado de Cartagena ordenando pregonar el arrendamiento de las tercias concedidas por Clemente VI. (Real de Gibraltar, 15 de septiembre de 1349). Veas Arteseros (1997), doc. 438, pp. 502-03.

93 Goñí Gaztambide (1958): 285.

94 Carta de Alfonso XI a los ejecutores de las tercias reales, décimas y bula de cruzada que Juan XXII le había otorgado en 1328. Arch. Cat. Sevilla, Caj. 5, no 8. García Fernández (1988), doc. 146, p. 34, doc. 146.

95 Vidal (1902), doc. 8335, p. 306.

96 Serrano (1912), Op. cit. 
1317 de recaudar tercias y décimas estipulaba que su monto global no podía exceder 3.000.000 de maravedíes ${ }^{97}$. El mero hecho de que se estableciese una cantidad límite tan alta indica que siempre fueron altos los ingresos derivados de dichos tributos.

No obstante, incluso con todas las antedichas fuentes de ingreso, Alfonso usualmente tuvo que negociar empréstitos de diversas entidades dentro y fuera de Castilla. En 1333, la Corona tomó prestada una cuantía de dineros de algunos caballeros de Valladolid, ciertos mercaderes de Burgos y de otros grupos en Madrid y en Toledo para reunir los recursos necesarios para la expedición de reconquista de Gibraltar ${ }^{98}$. Dos años después, cuando un nuevo brote de choques fronterizos se convirtió en un conflicto abierto entre Castilla y Navarra, Alfonso tuvo que obtener un nuevo empréstito, probablemente de algunos sectores de Valladolid, para costear el primer mes de la campaña ${ }^{99}$. Durante el interminable cerco de Algeciras, los apuros económicos de Castilla obligaron al rey a negociar un préstamo con Portugal, la Santa Sede y Francia. A pesar de que el rey Afonso IV (1325-57) no accedió a su pedido, Alfonso recibió en 1343 un préstamo del Papado por valor de 20.000 florines $^{100}$. También obtuvo del rey de Francia un empréstito superior a 50.000 florines, desembolsado en dos plazos ${ }^{101}$. Durante la misma campaña, la Corona recibió del obispado de Córdoba y el arzobispado de Sevilla préstamos en forma de grano; éste último añadió también un empréstito de 333.700 maravedíes. Alfonso acordó usar las cuantías recaudadas con las tercias reales y las décimas para satisfacer las deudas contraídas con el obispado de Córdoba y el arzobispado de Sevilla ${ }^{102}$. Finalmente, la Corona tuvo que obtener un préstamo de varios pueblos de la región de Extremadura, y posteriormente de unos mercaderes genoveses, cuando el Conde de Foix y sus contingentes gascones exigieron que se les pagasen sus servicios en Algeciras ${ }^{103}$.

Otro mecanismo, de naturaleza mucho más drástica, utilizado por el Rey para costear los siempre crecientes gastos militares fue la apropiación temporal de los ingresos procedentes de tributos locales, o la suspensión de exenciones fiscales. En otras palabras, el destinar directamente ciertos impuestos locales a las actividades militares y/o la recaudación de tributos en áreas que gozaban de libertad fiscal. Concretamente, para costear la flota castellana, Alfonso incautó temporalmente los ingresos de las diversas escribanías y notarías públicas ${ }^{104}$. Sin embargo, para

97 Biblioteca Nacional (Madrid), Ms. 13.097, fols. 5-20-56-71. Cit. Ladero Quesada (1993), 198-99.

98 CRÓNICA, cap. CXI.

99 Op. cit., cap. CXXVIII.

${ }^{100}$ Escritura otorgada por Clemente VI estipulando un empréstito a favor de Alfonso XI. (Aviñón, 14 de junio de 1343). Arch. Vat, Arm. C, $\mathrm{n}^{\circ} 318$, Alfonso XI ratifica la escritura de préstamo. (Real sobre Algeciras, 4 de julio de 1343). Arch. Vat. Castel. S. Angelo, Arm. 2, Caj. 4, nº 13. Serrano (1912), docs. 4, 6, pp. 27-32.

${ }^{101}$ CRÓNICA, cap. CCCIII.

102 Carta de Alfonso XI al arzobispo y cabildo de Sevilla. (Sevilla, 5 de febrero de 1345). Arch. Cat. Sevilla, Caj. 179, n³2; Alfonso XI escribe al arzobispo don Juan, al deán y al Cabildo de la Iglesia de Sevilla que le autoricen a cobrar las décimas del primer año, de los cuatro que el papa Clemente VI le había hecho merced para el cerco de Algeciras. (Madrid, 6 de octubre de 1345). Arch. Cat. Sevilla, Caj. 179, n 21; Carta de Alfonso XI a los recaudadores de las tercias reales del obispado de Córdoba ordenandoles que entregasen al obispo y al Cabildo de la Iglesia de esta ciudad, 200 cahices de trigo y 100 cahices de cebada, que la referida Iglesia le había prestado durante el cerco de Algeciras. (Sevilla, 27 de abril de 1346). Arch. Cat. Córdoba, Caj. p. n 246. García Fernández (1988): docs. 411, 420, 430, pp. 92, 94, 96.

${ }^{103}$ CRÓNICA, cap. CCCIII-CCCIV.

${ }^{104}$ Cartas de Alfonso XI a Astudillo, El Barco, Piedrafita y otros lugares de Alcorneja que ha decidido tomar todas las rentas de las escribanías y notarías públicas que le pertenecen para mantener la flota real en la mar (Valladolid, 12 de febrero de 1335). Martín Fuertes (1998), docs. 96-97, pp. 138-42; Carta de Alfonso XI al concejo de Sepúlveda que, a pesar de que el rey la había embargado para contribuir al sostenimiento de la flota, la escribanía pública corresponde al dicho concejo y debe ser desembargada. (Valladolid, 12 de junio de 1335). Sáez Sánchez, E. (1956), doc. 22, pp. 73-74; Carta de Alfonso XI en la que reconoce al concejo de Santo Domingo el derecho de escribanía propia que tenía embargada como las demás escribanías de sus reinos para mantenimiento de la flota (Valladolid, 25 de noviembre de 1335). López De Silanes et alii. (1989), doc. 27, p. 69; Carta de Alfonso XI devolviendo a Guetaria la escribanía pública que había embargado para el apoyo de la flota real (Valladolid, 25 de septiembre de 1336). Martínez Díez et alii. (1991), vol. 1, doc. 190 pp. 195-96; Carta del concejo de Baeza a Alfonso XI solicitando el aseguramiento de la venta de la escribanía pública de la ciudad 
muchos de estos pueblos la recuperación de sus escribanías no fue cosa fácil ya que la Corona, con sus constantes gastos militares, siempre encontró difícil renunciar a cualquier fuente de ingresos regular y solamente cedió después de largos esfuerzos por parte de las autoridades locales. En otros casos, y debido a las necesidades económicas relacionadas con sus ambiciones militares, la Corona suspendió los privilegios de ciertos grupos sociales o ciudades. En 1342, por ejemplo, ordenó que las libertades de Murcia en cuanto al comercio fuesen rescindidas por tres años debido a las recientes e incipientes campañas contra los musulmanes ${ }^{105}$.

Finalmente, en casos de extrema necesidad, Alfonso tuvo que ir más allá de la mera cesión de las rentas reales, llegando a vender partes del patrimonio real. En diciembre de 1349, la Corona vendió las áreas de Orozco y Llodio a Fernán Pérez de Ayala y la localidad de Bailén a Pedro Ponce de León a cambio de 140.000 maravedíes para financiar su campaña final para recuperar a Gibraltar. En enero del siguiente año vendió las villas de Valdemoro y Morata a Fernán Pérez de Portocarrero, ${ }^{106}$ y las de Palma y Villalba, en la región de Niebla, a Alvar Pérez de Guzmán por la cuantía de 130.000 maravedíes ${ }^{107}$. Leonor de Guzmán también se implicó en este proceso al adquirir Beteta y su torre en Cuenca por $200.000 \mathrm{mrs}^{108}$. Aunque estas transacciones rindieron elevadas cuantías, este método de recaudación de fondos podía ser muy perjudicial para el futuro político y económico de la hacienda real ya que beneficiaba principalmente a aquellos magnates capaces de aportar las grandes sumas de dinero necesarias.

El estudio presentado en las páginas precedentes ofrece tres importantes conclusiones. La primera es que incluso con el papel tan importante que desempeñaron Alfonso y sus oficiales en la financiación y administración de las campañas militares, los recursos reales nunca hubieran sido suficientes. Para cualquier operación militar de importancia, el monarca necesitaba y asumía que podía contar con el apoyo militar, logístico y monetario de la nobleza, los concejos urbanos y la Iglesia. Todos éstos, pese a sus protestas oficiales por la elevada carga fiscal, siempre tenían que asignar recursos considerables a las actividades militares, fuesen de naturaleza defensiva u ofensiva. Para la nobleza del siglo XIV la práctica de la guerra era una de sus raisons d'être más fundamentales y se esperaba que gran parte de sus rentas se destinase a asuntos militares. Alfonso fue capaz de movilizar todos estos recursos contra los benimerines y granadinos, en particular durante los últimos doce años de su vida, además de requerir por ley que todo magnate contribuyese con parte de sus riquezas, aun cuando recibieran libramientos $^{109}$. Los concejos urbanos, especialmente aquellos en zona fronteriza, debían proporcionar apoyo, beneficiándose también de las posibles recompensas, siempre que el monarca lo considerase necesario. En algunos casos, la contribución local podía exceder lo esperado, como cuando Baeza reclutó cien caballeros y cien ballesteros para acompañar a Alfonso en campaña en 1341. El concejo de Baeza impuso un tributo extraordinario para financiar sus tropas que al fin rindió 68.048 maravedíes, 11.224 más de lo previsto ${ }^{110}$. En cuanto a los prelados, ya hemos

\footnotetext{
(Baeza, 22 de diciembre de 1343). Rodríguez Molina et alii. (1983), vol. 1, doc. 54, p. 141; Carta de Alfonso XI en la que a petición del abad de Sahagún devuelve a su monasterio las escribanías públicas que había tomado para abastecer la flota. (Segovia, 24 de septiembre de 1344). AHN, Sec. Clero, Cpta. 932, doc. 2. González Crespo (1985), doc. 301, pp. 502-03; Privilegio de Alfonso XI en el que reconoce al concejo de Briviesca el derecho a percibir las rentas de la escribanía de la villa, una vez transcurridos los cinco años que, para mantenimiento de la flota, el rey se había reservado su percepción (Burgos, 2 de mayo de 1345). Díaz Martín (1997-99), vol. 2, doc. 488, pp. 229-31.

105 Albalá al concejo de Murcia. (Segovia, 29 de abril de 1342). Veas Arteseros (1997): doc. 396, p. 449.

${ }^{106}$ Real Academia de la Historia (Madrid), Col. Salazar y Castro, MS. D-10, fols. 249-50; MS. M-49, fols. 79v.-81rev.

107 Escritura de venta de Niebla y Villalba de Alfonso XI a Alvar Pérez de Gúzman. (Real sobre Gibraltar, 10 de enero de 1350). García Fernández (1988), doc. 474, p. 106.

108 AHN, Sec. Concejos, Memorial del pleito de Orozco, no 533-36. Cit. Grassotti (1990), 3459.

${ }^{109}$ CORTES (Ayuntamiento de Burgos, 1338), vol. 1, pp. 450-53.

110 Rodríguez Molina, J. (1983): vol. 1, doc. 45, pp. 123-25.
} 
visto cómo la Corona se apoderaba constantemente de los ingresos eclesiásticos. Pero también hay que recordar que aquéllos eran terratenientes y que contribuían a las actividades militares como señores territoriales. Un estudio más a fondo de cada uno de estos elementos no forma parte de los objetivos de este ensayo pero baste decir que su participación fue esencial ya que la guerra en sí se había convertido en una empresa que involucraba a todo el reino.

La segunda es que, más allá de recursos «privados» de individuos, localidades e instituciones, los gastos relacionados con las campañas militares habían ascendido a tales sumas que la Corona tenía por fuerza que desempeñar un papel central ya que no había nadie, incluso los más altos ricoshombres, que pudiera igualarla económicamente. Dicho de otra manera, cualquier acción militar salvo las defensas o conflictos muy localizados, tenía que contar con los recursos reales. En el siglo XIV, y en especialmente en el ámbito militar, la concepción del monarca como primus inter pares había perdido toda su importancia.

Tercera, y para finalizar, es innegable que Alfonso, a pesar de algunas graves derrotas y percances, pudo siempre superar las dificultades y se apuntó una impresionante serie de triunfos militares. Pero para comprender cómo todo ello fue posible hay que destacar que la habilidad de su gobierno para reunir los recursos financieros necesarios para financiar sus campañas es un aspecto fundamental de la grandeza de Alfonso como monarca y comandante militar. La experiencia de la pérdida de Gibraltar en 1333 por falta de dinero ciertamente le motivó a no permitir que algo similar volviese a ocurrir. Esta fue la principal razón por la cual Alfonso estuvo dispuesto a extraer tantos recursos fiscales extraordinarios de sus súbditos y emplearlos en su ambicioso programa militar. Sin estas medidas fiscales, Alfonso no habría vencido a sus enemigos, tanto domésticos como foráneos. En el análisis final de los triunfos del Rey Don Alfonso el Onceno, y sin minusvalorar su fuerza de carácter, su destreza como gobernante o su valor para enfrentarse a tantos desafíos, debemos también asignar un enorme mérito a sus tesoreros, recaudadores y contadores que, tal vez sin gozar de la gloria en los campos de batalla o frente a las murallas enemigas, tuvieron un papel de vital importancia en sus victorias.

\section{BIBLIOGRAFÍA}

Alarcón y Santón, M. et alii. (1940): Los documentos árabes diplomáticos de Archivos de la Corona de Aragón. Madrid, Escuelas de Estudios Árabes de Madrid y Granada.

Álvarez Borge, I. (1987): El feudalismo castellano y el libro becerro de las behetrías: la merindad de Burgos. León: Universidad de León.

Benavides, A. (1860): Memorias de Don Fernando IV de Castilla. 2 vols. Madrid: Imprenta J. Rodríguez.

Benito Ruano, E. (1992): Colección diplomática del Archivo del Excmo. Ayuntamiento de Avilés (siglos XII-XV), 1155-1495. Avilés, Ayuntamiento de Avilés.

Cabañas González, M. D. (1980): La caballería popular en Cuenca durante la baja Edad Media. Madrid: Prensa Española.

Carriazo Arroquia, J. M. (1975): Colección diplomática de Quesada. Jaén, Instituto de Estudios Giennenses, CSIC.

Contamine, P. (1984): War in the Middle Ages. Trans. Michael Jones. Cambridge, Blackwell.

CRÓNICA DEL REY DON ALFONSO EL ONCENO. Crónicas de los reyes de Castilla. (1875): Ed. D. C. Rosell. Biblioteca de Autores de España 66. Madrid, M. Rivadeneyra, 172-392.

CRÓNICA DEL REY DON FERNANDO IV. Crónicas de los Reyes de Castilla. (1875): Ed. D. C. Rosell. Biblioteca de Autores de España 66. Madrid, M. Rivadeneyra, 92-170.

Díaz Martín, L. V. (1997-99): Colección documental de Pedro I de Castilla, 1350-1369. 4 vols. Documentos para la Historia de Castilla y León. Salamanca: Junta de Castilla y León / Caja Duero.

France, J. (1999): Western Warfare in the Age of the Crusades. Ithaca, NY, Cornell University Press.

García Barrios, A. et alii. (1982): Documentación medieval del archivo municipal de Alba de Tormes, Salamanca, Universidad de Salamanca y Ayuntamiento de Alba de Tormes. 
García Barrios, A. (1986): Documentación medieval de los archivos de Béjar y Candelario. Salamanca: Diputación de Salamanca.

García Fernández, M. (1988): «Regesto documental andaluz de Alfonso XI (1312-1350)». Historia, Instituciones, Documentos XV: 1-125.

Gil Farrés, O. (1976): Historia de la moneda española, $2^{\mathrm{a}}$ ed. Madrid. Apartado.

Giménez Soler, A. (1932): Don Juan Manuel. Biografía y estudio crítico. Zaragoza: Tip. La Académica.

González Crespo, E. (1985): Colección documental de Alfonso XI. Sección del Clero. Madrid, Universidad Complutense.

Goñí Gaztambide, J. (1958): Historia de la Bula de la Cruzada de España. Vitoria, Publicaciones de Vitoria.

GRAN CRÓNICA DE ALFONSO XI. 2 vols. (1977): Ed. D. Catalán. Fuentes Cronísticas de la Historia de España, IV. Madrid: Editorial Gredos

Grassotti, H. (1990): «Los apremios fiscales de Alfonso XI». Historia económica y de las instituciones financieras en Europa. Ed. Manuel J. Peláez. Málaga, Universidad de Málaga, 3435-62.

Hamilton, Earl J. (1936): Money, Prices and Wages in Valencia, Aragon and Navarre, 1351-1500. Cambridge, Harvard Press.

Ladero Quesada, M. A. (1973): La Hacienda Real de Castilla en el siglo XIV. Santa Cruz de Tenerife, Universidad de la Laguna.

Ladero Quesada, M. A. (1993): Fiscalidad y poder real en Castilla (1252-1369). Madrid: Editorial Complutense.

López De Ayala, P. Crónica del Rey Don Enrique. Crónicas. (1991). Ed. J. L. Martín. Barcelona, Planeta.

López De Silanes C. et alii. (1989): Colección diplomática calceatense. Archivo municipal (años 12071498). Logroño, CSIC-Instituto de Estudios Riojanos, Gobierno de la Rioja.

Martín Fuertes, J. A. (1995): Colección documental del archivo de la catedral de León. XI. (1301-1350). Fuentes y Estudios de Historia Leonesa, 59. León, Centro de Estudios e Investigación San Isidoro, Caja de Inversiones, Ahorros y Monte de Piedad, Archivo Histórico Diocesano.

Martín Fuertes, J. A. (1998): Colección documental del archivo municipal de León (1219-1400). León: Centro de Estudios e Investigación San Isidoro, Caja España de Inversiones, Archivo Histórico Diocesano.

Martínez Díez, G. (1981): Libro becerro de las behetrías. 3 vols. León, Centro de Estudios e Investigación «San Isidro.»

Martínez Díez, G. et alii. (1991): Colección de documentos medievales de las villas guipuzcoanas (1200-1369). San Sebastián, Diputación foral de Gipuzkoa.

Molina Molina, A. L. (1978): Documentos de Pedro I. Colección de documentos para la historia del reino de Murcia. Vol. VII. Murcia: Real Academia Alfonso X el Sabio y CSIC.

Moxó, S. (1963): La alcabala; sobre sus orígenes, concepto y naturaleza. Madrid, CSIC.

O’callaghan, J. F. (1989): The Cortes of Castile-León, 1188-1350. Philadelphia: University of Pennsylvania Press.

Pareda Llarena, J. (1980): Documentación de la catedral de Burgos (1254-1293) (1294-1316). Burgos, J.M. Garrido Garrido.

REAL ACADEMIA DE LA HISTORIA (1807). Las Siete Partidas del rey Don Alfonso el Sabio, cotejada con varios códices antiguos. 3 vols. Madrid, Imprenta Real.

REAL ACADEMIA DE LA HISTORIA (1882-1903). Cortes de los antiguos reinos de León y de Castilla. 5 vols. Madrid: M. Rivadeneyra.

Rodríguez Molina, J. et alii. (1983): Colección diplomática de Baeza (Siglos XIII-XV). 2 vols. Jaén, Universidad de Granada.

Rodríguez Molina, J. (1994): Colección documental del archivo municipal de Úbeda. II (Siglo XIV). Granada, Universidad de Granada, Ayuntamiento de Úbeda.

Sáez Sánchez, E. (1956): Colección diplomática de Sepúlveda. I. (1076-1454). Segovia: Diputación provincial de Segovia.

Sánchez Martínez, M. (1993): «Guerra, avituallamiento del ejército y carestías en la Corona de Aragón: la provisión de cereal para la expedición granadina de Alfonso el Benigno (1329-1333)». Historia, Instituciones, Documentos XX: 523-49. 
Serrano, L. (1907): Cartulario del Infantado de Covarrubias, Fuentes para la Historia de Castilla vol. 2. Valladolid: Cuesta.

Serrano, L. (1912): «Alfonso XI y el Papa Clemente VI durante el cerco de Algeciras». Cuadernos de los Trabajos de la Escuela Española de Arqueología e Historia de Roma III: 1-35.

Spufford, P. et alii. (1986): Handbook of Medieval Exchange. Londres, Royal Historical Society.

Torremocha Silva, A. (1994): Algeciras entre la Cristiandad y el Islam: estudio sobre el cerco y la conquista de Algeciras por el rey Alfonso XI de Castilla, así como de la ciudad y sus términos hasta el final de la Edad Media. Algeciras, Instituto de Estudios Campogibraltareños.

Ubieto Arteta, A. (1961): Colección diplomática de Cuéllar. Segovia: Diputación Provincial de Segovia.

Veas Arteseros, F. A. (1997): Documentos de Alfonso XI. Colección de documentos para la historia del reino de Murcia. VI. Murcia: Real Academia Alfonso X El Sabio y CSIC.

Vidal, J. M. (1902): Benoit XII (1334-1342). Lettres Communes. 3 vols. Paris, Bibliotheque des Ecoles Français d'Athenes et de Rome.

\section{APÉNDICE}

Tabla 1. Monedas foreras y servicios extraordinarios recaudados durante el reinado de Alfonso XI

\begin{tabular}{|c|c|}
\hline Año & Tipo \\
\hline 1314 & 5 Servicios divididos entre los tutores del Rey \\
\hline 1315 & 3 Ayudas divididas entre los tutores del Rey \\
\hline 1316 & Servicio de 1.000 .000 mrs. para Infante Pedro \\
\hline 1317 & 5 Servicios divididos entre los tutores del Rey \\
\hline 1318 & Moneda Forera (Ordinaria) \\
\hline 1318 & 5 Servicios divididos entre los tutores del Rey \\
\hline 1320 & $\begin{array}{l}\text { 7,5 Servicios para el Infante Juan Manuel de parte de los que lo tomaban como tutor y } 6 \\
\text { Servicios al Infante Felipe de parte de los que lo reconocían como tutor }\end{array}$ \\
\hline 1323 & 5 Servicios para el Infante Juan de parte de los que tomaban como tutor \\
\hline 1324 & 5 Servicios para el Infante Juan Manuel de parte de los que tomaban como tutor \\
\hline 1325 & Moneda Forera (Ordinaria) \\
\hline 1325 & 5 Servicios para el Rey \\
\hline 1329 & Moneda Forera \\
\hline 1329 & 4 Ayudas para el Rey \\
\hline 1332 & $\begin{array}{l}\text { Servicio para el Rey sobre todo el reino y } 4 \text { Servicios recaudados en las territorios bajo la } \\
\text { autoridad de Orden de Santiago en Toledo y Cuenca }\end{array}$ \\
\hline 1336 & Moneda Forera \\
\hline 1336 & 5 Servicios para el Rey \\
\hline 1340 & Servicio parcial para el Rey \\
\hline $1341-42$ & Moneda Forera \\
\hline 1343 & Moneda Forera (Parcial) \\
\hline 1349 & Moneda Forera \\
\hline 1349 & 2 Servicios para el Rey \\
\hline
\end{tabular}

